\title{
Synthesis, Characterization and Ion-Exchange Properties of Terpolymer Resin-II Derived from p-Hydroxybenzaldehyde, Thiourea and Ethylene Glycol
}

\author{
AMIT N. GUPTA ${ }^{1}$, VINAY V. HIWASE ${ }^{2 *}$ and ASHOK B. KALAMBE ${ }^{1}$ \\ ${ }^{1}$ Department of Chemistry, Institute of Science, R. T. Road, Nagpur-440001, India \\ ${ }^{2}$ Arts, Commerce and Science College, Arvi-442201, Dist.-Wardha, India \\ vvhiwase@gmail.com
}

Received 4 March 2013 / Accepted 30 April 2013

\begin{abstract}
Ion-exchange resin (HBTE-II) was synthesized by polycondensation in the presence of polyphosphoric acid as a catalyst using monomers $p$-hydroxybenzaldehyde $(0.2 \mathrm{M})$, thiourea $(0.1 \mathrm{M})$ and ethylene glycol $(0.4 \mathrm{M})$ at $120^{\circ} \mathrm{C}$. The terpolymer resin was characterized by elemental analysis, the number average molecular weight, UV-Visible, IR and ${ }^{1} \mathrm{H}$ NMR spectrum. Chelating ion-exchange properties of this copolymer were studied for $\mathrm{Bi}^{3+}, \mathrm{Sb}^{3+}, \mathrm{Zn}^{2+}$ and $\mathrm{Mg}^{2+}$ ions. $\mathrm{A}$ batch equilibrium method was employed in the study of the selectivity of metal ion uptake involving the measurements of the distribution of a given metal ion between the polymer sample and a solution containing the metal ion. The study was carried out over a wide $\mathrm{pH}$ range and in media of various ionic strengths. The metal ions were estimated spectrophotometrically. The HBTE-II terpolymer resin was found to be selective chelating ion-exchange resin for $\mathrm{Sb}^{3+}, \mathrm{Bi}^{3+}$ and $\mathrm{Zn}^{2+}$.
\end{abstract}

Keywords: Polycondensation, Ion-exchange, Distribution ratio, Rate of metal ion uptake, Batchequilibrium method

\section{Introduction}

Ion-exchangers are used in great application for selective removal of waste material in nuclear plants, analytical chemistry, hydrometallurgy, separation of radioisotopes, metal pollution control and water treatment ${ }^{1-2}$. Quality of water obtained by an ion - exchange process is like as the de-ionized water and is the best for all industrial purposes, especially boilers, heat exchangers, pharmaceutical industries. Ion-exchangers remove not only heavy metal ions from water but also all positive and negative ions too depending on functional groups on the matrix of exchangers. Synthetic resins derived from hydroxyl and amino compounds have attention of research coworkers because of their versatile use an ionexchangers, photographic binders and thermal stabilizers ${ }^{3}$.

Rahangdale et al. $^{4}$ synthesized 2,4-dihydroxyacetophenone-dithiooxamide-formaldehyde terpolymer and chelating ion-exchange properties have also been studied employing the batch equilibrium method and reported the overall rate of metal uptake follows the order: $\mathrm{Fe}^{3+}>\mathrm{Cu}^{2+}>\mathrm{Ni}^{2+}>\mathrm{Co}^{2+}=\mathrm{Zn}^{2+}$. 
Azarudeen et al. ${ }^{5}$ synthesized phthalic acid-urea-formaldehyde terpolymer resin and proved to be a selective chelation ion-exchange terpolymer for metals. A batch equilibrium method was employed to study the selectivity and sorption capacity of the resin towards certain divalent metal ions such as $\mathrm{Pb}^{2+}, \mathrm{Zn}^{2+}, \mathrm{Cu}^{2+}, \mathrm{Ni}^{2+}, \mathrm{Ba}^{2+}, \mathrm{Co}^{2+}$ and $\mathrm{Mn}^{2+}$ in various electrolyte concentrations, wide $\mathrm{pH}$ ranges and different time intervals. Hence the resin used to recover certain metal ions from waste solutions and for the purpose of purification of wastewater and removal of iron from boiler water.

Pancholi et al. synthesized polymer by condensation of 2-hydroxy-4-methoxyacetophenone-thiourea-trioxane ${ }^{6}$. They studied ion-exchange properties of terpolymers for $\mathrm{Cu}^{2+}$, $\mathrm{Ni}^{2+}, \mathrm{Co}^{2+}, \mathrm{Mn}^{2+}, \mathrm{Zn}^{2+}, \mathrm{Fe}^{2+}$ and $\mathrm{UO}_{2}{ }^{2+}$ ions over the $\mathrm{pH}$ range 3.5-5.5 in media of various ionic strengths. They reported that the polymer showed a higher selectivity for $\mathrm{Cu}^{2+}, \mathrm{Fe}^{2+}$ and $\mathrm{UO}_{2}{ }^{2+}$ ions over any other ion.

The present communication deals with synthesis, characterization and ion-exchange properties of HBTE-II terpolymer resin derived from $p$-hydroxybenzaldehyde, thiourea and ethylene glycol.

\section{Experimental}

All chemicals were AR grade or chemically pure grade, $p$-hydroxybenzaldehyde, thiourea, ethylene glycol and polyphosphoric acid were procured from s.d. fine chemicals, India.

\section{Synthesis of HBTE-II terpolymer}

A terpolymer resin abbreviated as HBTE-II was synthesized by polycondensation of monomers $p$-hydroxybenzaldehyde, thiourea and ethylene glycol in the presence of polyphosphoric acid. To a well-stirred and ice-cooled mixture of $p$-hydroxybenzaldehyde $(0.2 \mathrm{M})$, thiourea $(0.1 \mathrm{M})$ and ethylene glycol $(0.4 \mathrm{M})$, polyphosphoric acid (PPA) was added slowly with continuous stirring as a catalyst. The reaction mixture was left at room temperature for 30 minutes then heated on oil bath at $120{ }^{0} \mathrm{C} \pm 2{ }^{0} \mathrm{C}$ for $5.30 \mathrm{~h}$. The reaction mixture was cooled, poured on crushed ice and left over night ${ }^{7-8}$. The reddish brown solid was separated. The crude product was squeezed with ether so as to remove thiourea-glycol copolymer which might be formed along with HBTE-II. The terpolymer was further purified by dissolving in $0.1 \mathrm{~N} \mathrm{NaOH}$ solution and reprecipitated by drop wise addition of 1:1 $\mathrm{HCl}$ with constant stirring. The product was washed several times with hot water and cold water. The product was air dried and kept in vacuum over silica gel. Yield was found to be $80 \%$. The scheme of synthesis of HBTE-II is shown in Figure 1.

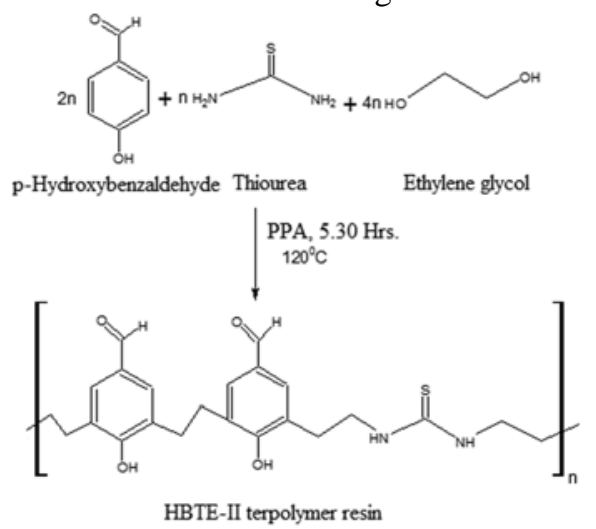

Figure 1. Scheme of synthesis of HBTE-II terpolymer resin 


\section{Ion exchange experimental procedures}

The ion-exchange property of the HBTE-II terpolymer resin was determined by the batch equilibrium method. Estimation of metal carried out using a spectrophotometer.

\section{Procedure for determination of the effect of electrolyte on metal uptake}

The resin sample (25 mg) was suspended in an electrolyte solution of required concentration $(25 \mathrm{~mL})$ for $24 \mathrm{~h}$. The $\mathrm{pH}$ of the solution was to 6.0 using $0.1 \mathrm{M} \mathrm{HNO}_{3}$ or $0.1 \mathrm{M} \mathrm{NaOH}$. To this solution $5 \mathrm{~mL}$ of $0.1 \mathrm{M}$ metal nitrate solution added at room temperature and $\mathrm{pH}$ was adjusted to the required value. The mixture was stirred again at room temperature for 24 hours and filtered. Solids were washed and washings were quantitatively combined with the filtrate. The metal content was determined by a spectrophotometer. The amount of metal exchanged was determined from the difference between reading in blank and actual experiments ${ }^{9-11}$. The amounts of metal ion in mg per $g$ of resin were calculated in the presence of $\mathrm{NaCl}, \mathrm{NaNO}_{3}, \mathrm{NaClO}_{4}$ and $\mathrm{Na}_{2} \mathrm{SO}_{4}$ electrolyte for metal ions $\mathrm{Sb}^{3+}, \mathrm{Bi}^{3+}, \mathrm{Zn}^{2+}$ and $\mathrm{Mg}^{2+}$.

\section{Procedure for evaluation of rate of metal ion uptake}

In order to determine optimum time required to reach the equilibrium the experiments were performed as above but here metal ion uptake was estimated as a function of time in hrs in the presence of $1.5 \mathrm{M} \mathrm{NaNO}_{3}$ solution $(25 \mathrm{~mL})$. It was assumed that the equilibrium state was established within $24 \mathrm{~h}$. The rate of metal uptake was expressed in terms of percent metal uptake related to a state of equilibrium ${ }^{12-14}$ by the formula (1).

$$
\% \text { metal uptake }=\frac{\mathrm{mg} \text { of metal sorbed in given time }}{\mathrm{mg} \text { of metal sorbed in } 24 \mathrm{~h}} \times 100
$$

\section{Procedure to study the effect of $\mathrm{pH}$ on metal uptake}

The resin sample $25 \mathrm{mg}$ was allowed to swell for 24 hours in $1.5 \mathrm{M} \mathrm{NaNO}_{3}$ solution. The $\mathrm{pH}$ was adjusted to the required value as above. $5 \mathrm{~mL}$ of $0.1 \mathrm{M}$ metal nitrate solution was added. The $\mathrm{pH}$ was maintained again and stirred for $24 \mathrm{~h}$. Metal was estimated by a spectrophotometer to determine the distribution ratio (D) between polymer phase and solution phase $\mathrm{e}^{15-17}$. The distribution ratio was calculated by the formula (2),

$$
\mathrm{D}=\frac{\text { weight }(\mathrm{mg}) \text { of metalions taken up by } 1 \mathrm{~g} \text { of polymer }}{\text { weight }(\mathrm{mg}) \text { of metalions present in } 1 \mathrm{ml} \text { of soluton }}
$$

\section{Results and Discussion}

HBTE-II terpolymer resin was reddish brown in color and soluble in DMSO and $\mathrm{NaOH}$ solution where as insoluble in acids and common organic solvents.

\section{Elemental analysis and molecular weight determination $(\overline{\mathrm{Mn}})$}

Elemental analysis has been carried out in CIMFR unit, Nagpur, by analytical functional testing Vario MICRO CHN elemental analyzer (Germany). The elemental analysis data of HBTE-II terpolymer are tabulated in Table 1.

\begin{tabular}{|c|c|c|c|c|c|c|c|c|}
\hline \multicolumn{2}{|c|}{$\%$ C } & \multicolumn{2}{|c|}{$\% \mathrm{H}$} & \multicolumn{2}{|c|}{$\% \mathrm{~N}$} & \multicolumn{2}{|c|}{$\% \mathrm{~S}$} & \multirow{2}{*}{$\begin{array}{l}\text { Mol. Formula } \\
\text { repeat unit }\end{array}$} \\
\hline Calc & Found & Calc & Found & Calc & Found & Calc & Found & \\
\hline 64.77 & 64.72 & 6.14 & 6.10 & 6.57 & 6.53 & 7.52 & 7.50 & $\left(\mathrm{C}_{23} \mathrm{H}_{26} \mathrm{~N}_{2} \mathrm{O}_{4} \mathrm{~S}\right)_{\mathrm{n}}$ \\
\hline
\end{tabular}

Table 1. Elemental analysis data of HBTE-II terpolymer resin 
The number average molecular weight $(\overline{M n})$ was determined by non-aqueous conductometric titration in DMSO using $0.1 \mathrm{M} \mathrm{KOH}$ in absolute alcohol as titrant ${ }^{18}$. The degree of polymerization $(\overline{D p})$ and the number average molecular weight $(\overline{M n})$ have been calculated using following equations (3) and (4),

$$
\begin{gathered}
\overline{\mathrm{Dp}}=\frac{\text { Total Meq of base required for last break }}{\text { Meq of base requires for first break }} \\
\overline{M n}=\overline{D p} \times \text { Repeat unit weight }
\end{gathered}
$$

The repeating unit weight was obtained from elemental analysis. The molecular weight determination data of HBTE-II terpolymer are tabulated in Table 2.

Table 2. Molecular weight determination data of HBTE-II terpolymer resin

\begin{tabular}{ccccc}
\hline $\begin{array}{c}\text { Meq. of KOH/100 g } \\
\text { of resin for first } \\
\text { break }\end{array}$ & $\begin{array}{c}\text { Meq. of KOH/100 g } \\
\text { of resin for last } \\
\text { break }\end{array}$ & $\overline{D p}$ & $\begin{array}{c}\text { Molecular } \\
\text { weight of } \\
\text { repeat unit }\end{array}$ & $\begin{array}{c}\text { Molecular } \\
\text { weight }(\overline{M n})\end{array}$ \\
\hline 380 & 5280 & $13.90 ~ 14$ & 426 & 5964 \\
\hline
\end{tabular}

IR spectra

IR spectrum of HBTE-II terpolymer was recorded at department of pharmacy, RTM Nagpur University, Nagpur, using FT-IR spectrophotometer, Shimadzu, model No-8101A. FT-IR spectrum of synthesized terpolymer is shown in Figure 2.

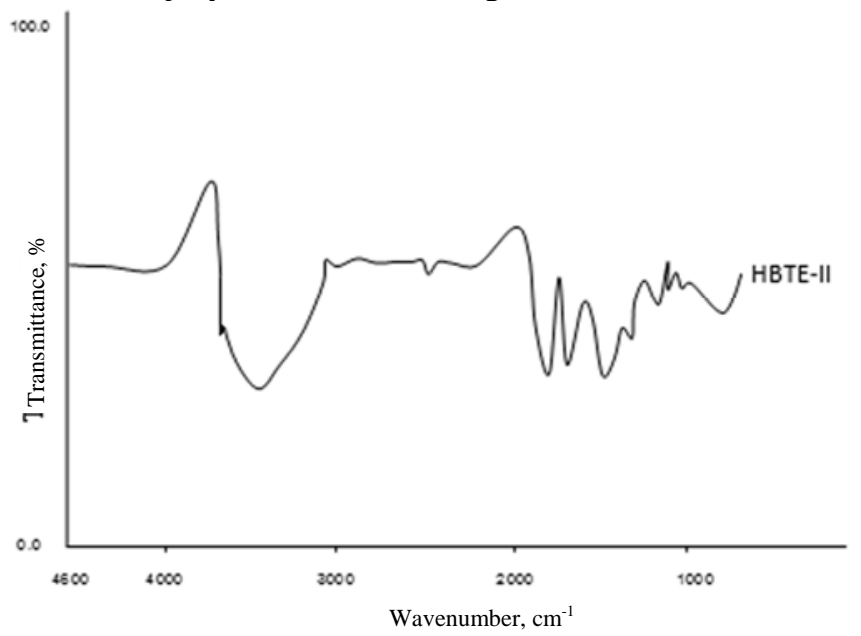

Figure 2. IR-spectra of HBTE-II terpolymer resin

A medium peak at $3575 \mathrm{~cm}^{-1}$ was clearly due to $\mathrm{N}-\mathrm{H}$ stretching of secondary amide group. A broad absorption band appeared in the region $3434 \mathrm{~cm}^{-1}$ was assigned to the stretching vibrations of phenolic hydroxyl $(-\mathrm{OH})$ group exhibiting intermolecular hydrogen bonding. The presence of peaks at 2745, $2916 \mathrm{~cm}^{-1}$ was due to the $-\mathrm{C}-\mathrm{H}$ - stretch in the aldehyde (doublet due to Fermi resonance). The peaks at $1686 \mathrm{~cm}^{-1}$ and $1655 \mathrm{~cm}^{-1}$ assigned due to the $\mathrm{C}=\mathrm{O}$ band (an aldehyde). The presence of peak at $1601 \mathrm{~cm}^{-1}$ was due to aromaticring. The $\mathrm{N}-\mathrm{H}$ bends and $\mathrm{C}-\mathrm{N}$ were stretching band at $1560 \mathrm{~cm}^{-1}$ also be observed. A sharp medium peak at $1509 \mathrm{~cm}^{-1}$ was ascribed to $\mathrm{N}-\mathrm{H}$ bending of secondary amide group. A peak appeared at $1458 \mathrm{~cm}^{-1}$ was due to methylene bridge coupled with aromatic ring. A peak 
appeared at $1383 \mathrm{~cm}^{-1}$ was assigned to in plane bending vibration of phenolic -OH. $1345 \mathrm{~cm}^{-1}$ appeared due to aldehyde $\mathrm{C}-\mathrm{H}$ bend. 1, 2, 3, 5- tetra substitution of aromatic ring was assigned due to the peaks at 1220, 1080 and $963 \mathrm{~cm}^{-1}$. The bands appeared at $1297 \mathrm{~cm}^{-1}$ and $1285 \mathrm{~cm}^{-1}$ were attributed to C-N stretching in secondary amide. A strong peak appeared at $1200 \mathrm{~cm}^{-1}$ was due to $\mathrm{C}=\mathrm{S}$ stretching vibration. The presence ${ }^{19-20}$ of peak at $831 \mathrm{~cm}^{-1}$ was due to the $-\mathrm{CH}_{2}$ - (wagging). IR spectrum data of HBTE-II terpolymer is tabulated in Table 3.

Table 3. IR spectrum data of HBTE-II terpolymer resins

\begin{tabular}{cl}
\hline \multicolumn{1}{c}{ Observed frequency, $\mathrm{cm}^{-1}$} & \multicolumn{1}{c}{ Assignment } \\
\hline $3575(\mathrm{~m})$ & NH-stretching- secondary amide \\
$3434(\mathrm{~b})$ & $\begin{array}{l}\text { Phenolic -OH group with intermolecular } \\
\text { polymeric association }\end{array}$ \\
$2745(\mathrm{w}), 2916(\mathrm{~m})$ & C-H stretches in aldehyde (doublet due to Fermi \\
$1686(\mathrm{~m}), 1655(\mathrm{~s})$ & resonance) \\
$1601(\mathrm{w})$ & C=O band (aldehyde) \\
$1560(\mathrm{w})$ & N-H bending \\
$1509(\mathrm{~s})$ & Secondary amide \\
$1458(\mathrm{~m})$ & CH bending \\
$1383(\mathrm{~m})$ & Phenolic-OH in plane bending \\
$1345(\mathrm{~m})$ & Aldehydic C-H bending \\
$1297(\mathrm{w}), 1285(\mathrm{~m})$ & C-N stretching band -CSNH- \\
$1220(\mathrm{~m}), 1080(\mathrm{~m}), 963(\mathrm{w})$ & $1,2,3,5$ tetra substituted aromatic ring \\
$1200(\mathrm{~s})$ & C=S stretching vibration \\
$831(\mathrm{w})$ & $-\mathrm{CH}$-wagging \\
\hline
\end{tabular}

(b) = Broad, $(s)=$ Sharp, $(w)=$ Weak, $(m)=$ medium

\section{${ }^{1}$ H NMR spectrum}

${ }^{1} \mathrm{H}$ NMR spectrum of HBTE-II terpolymer using DMSO-d ${ }^{6}$ solvent was scanned on NMR spectrophotometer SAIFNM100820A, at Sophisticated Test and Instrumentation Center (STIC), Cochin University, Kerala, India. The ${ }^{1} \mathrm{H}$ NMR spectrum of HBTE-II terpolymer is shown in Figure 3.

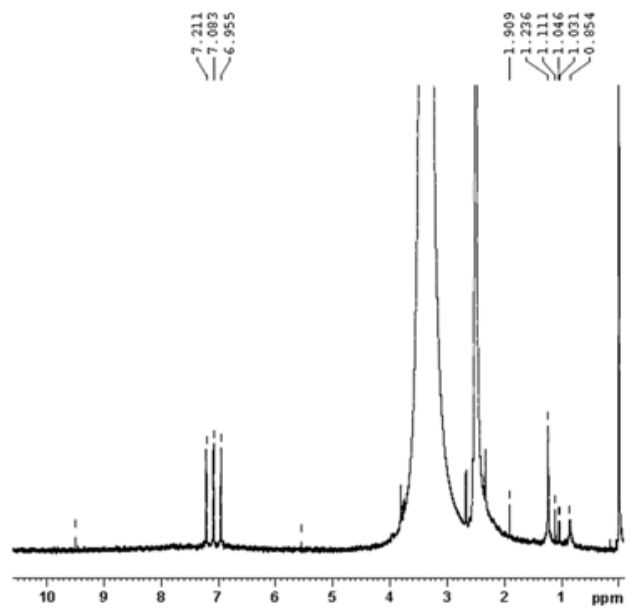

Figure 3. ${ }^{1} \mathrm{H}$ NMR spectra of HBTE-II terpolymer resin 
A signal at $2.5 \delta$ ppm was due to DMSO solvent. The medium singlet at $2.6 \delta$ ppm due to the methylene proton of the $\mathrm{Ar}-\mathrm{CH}_{2}$ bridge. A singlet observed in the region $3.8 \delta \mathrm{ppm}$ was due to the methylene proton of an $\mathrm{Ar}-\mathrm{CH}_{2}-\mathrm{NH}$ moiety. A singlet observed in the region $5.5 \delta \mathrm{ppm}$ attributed to the protons in $-\mathrm{NH}$ linkage. The peaks in the region of $7.1 \delta \mathrm{ppm}$ assigned to the protons in the aromatic ring. The signal at $9.5 \delta \mathrm{ppm}$ was assigned to the $\mathrm{OH}$ group of $\mathrm{Ar}-\mathrm{OH}$ and it indicates the intramolecular hydrogen bonding between -OH group of Ar-OH and - $\mathrm{NH}$ group of the terpolymer resin ${ }^{21-23}$.

\section{UV-Visible spectrum}

UV-Visible spectrum of HBTE-II terpolymer in DMSO solvent recorded by UV-Visible double beam spectrophotometer, Schimadzu, model-1800 at the department of nanotechnology, Shivaji Science College, Nagpur. The electronic spectrum of the HBTE-II terpolymer is shown in Figure 4 and UV-Visible spectrum data is presented in Table 4.

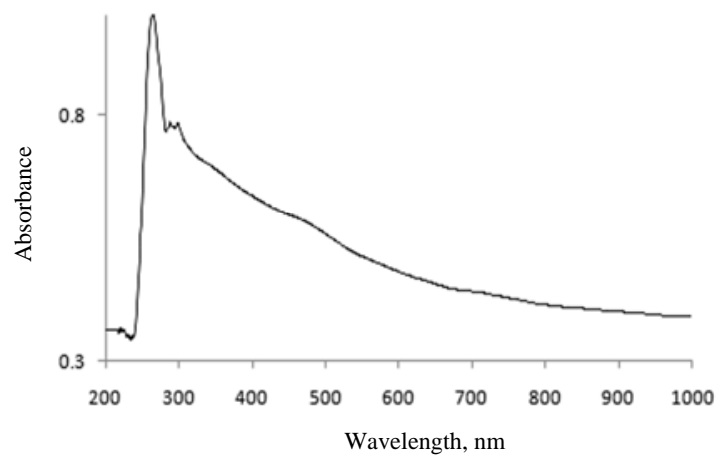

Figure 4. UV-Visible spectra of HBTE-II terpolymer resin

A peak at $220.5 \mathrm{~nm}$ was assigned to $n-\sigma^{*}$ transition was due to C-NH- moiety and peak at $264.5 \mathrm{~nm}$ was assigned to $\pi-\pi^{*}$ due to the aromatic ring. $n-\pi^{*}$ transitions at $288.0 \mathrm{~nm}$ and $298.0 \mathrm{~nm}$, these were due to $>\mathrm{C}=\mathrm{S}$ in amide linkage and $-\mathrm{CHO}$ moiety ${ }^{24}$.

Table 4. UV-Visible spectrum data of HBTE-II terpolymer

\begin{tabular}{ccl}
\hline Transition & Wavelength, nm & Group / moiety assigned \\
\hline $\mathrm{n}-\sigma^{*}$ & 220.5 & C-NH- moiety \\
$\pi-\pi^{*}$ & 264.5 & Aromatic ring \\
$\mathrm{n}-\pi^{*}$ & 288.0 & $>\mathrm{C}=\mathrm{S}$ in amide linkage \\
& 298.0 & $-\mathrm{CHO}$ group \\
\hline
\end{tabular}

\section{Ion-exchange properties}

To ascertain the selectivity of HBTE-II, The ion-exchange properties of resin were studied with reference to the influence of various electrolytes, the rate of metal uptake and distribution of metal ions between the resin and solution. The results of the batch equilibrium study carried out with the HBTE-II terpolymer resin is presented in Table 5-6 and in graph Figure 5. Estimation of metal carried out using a spectrophotometer.

\section{Effect of electrolytes on the metal uptake}

Effect of electrolyte on metal uptake is summarized in Table 5. The inspection of the data reveals that the amount of metal ions taken up in the presence of $\mathrm{NaNO}_{3}$ is larger than $\mathrm{NaCl}$, $\mathrm{Na}_{2} \mathrm{SO}_{4}$ and $\mathrm{NaClO}_{4}$. For the metal ions $\mathrm{Sb}^{3+}, \mathrm{Bi}^{3+}, \mathrm{Mg}^{2+}$ and $\mathrm{Zn}^{2+}$, the exchange capacity 
increases with increases in the concentration of $\mathrm{NO}_{3}{ }^{-}, \mathrm{ClO}_{4}{ }^{-}$and $\mathrm{Cl}^{-}$, whereas it decreases with increases in concentration of $\mathrm{SO}_{4}{ }^{2-}$. This is due to the fact that metal ions under study form kinetically more inert compound with respect to $\mathrm{SO}_{4}{ }^{2-}$ as compared to metal-resin interaction. On a contrary increase in the metal exchange capacity of metal resin in the presence of $\mathrm{NO}_{3}{ }^{-}, \mathrm{ClO}_{4}{ }^{-}$and $\mathrm{Cl}^{-}$attributed to high kinetically inert metal-resin interaction as compared to metal-electrolyte interactions ${ }^{25-27}$.

Table 5. Effect of different electrolytes on the uptake of several metal ions on HBTE-II resin

\begin{tabular}{cccccc}
\hline \multirow{3}{*}{ Metal ion } & $\begin{array}{c}\text { Electrolyte } \\
\text { Conc. Mol/L }\end{array}$ & \multicolumn{4}{c}{ Wt. of metal ion (mg) exchanged per of gram resin in the } \\
\cline { 3 - 6 } presence of different electrolytes
\end{tabular}

Metal nitrate solution $=0.1 \mathrm{Mol} / \mathrm{L}, 5 \mathrm{~mL}$; Electrolyte $=25 \mathrm{~mL}$; Equilibrium state $=24 \mathrm{~h}$; Wt. of resin=25 mg; Temperature $=$ Room temperature; Metal ions were estimated spectrophotometrically, Error $= \pm 1.5 \%$

Rate of metal uptake

From the graph present in Figure 5, initially the rate of metal uptake was steeply increased, become gradual and finally remain constant as the time passes for all metal ions. For $\mathrm{Sb}^{3+}$ and $\mathrm{Mg}^{2+}$ the equilibrium was reached within $7 \mathrm{~h}$ whereas for $\mathrm{Bi}^{3+}$ and $\mathrm{Zn}^{2+}$, the time required to reach equilibrium was $6 \mathrm{~h}$. The rates of metal uptake for trivalent metal ions $\left(\mathrm{Bi}^{3+}\right.$ and $\mathrm{Sb}^{3+}$ ions) were higher than divalent metal ions $\left(\mathrm{Mg}^{2+} \text { and } \mathrm{Zn}^{2+} \text { ions }\right)^{28-30}$. The rate of metal ion uptake decreases in order $\mathrm{Bi}^{3+}>\mathrm{Sb}^{3+}>\mathrm{Zn}^{2+}>\mathrm{Mg}^{2+}$.

Distribution ratio of metal ions at different $\mathrm{pH}$

The effect of $\mathrm{pH}$ on a distribution ratio of metal ions between resin and solution phase can be explained by Table 6 . The study was carried out in the limit of higher $\mathrm{pH}$ in order to 
prevent hydrolysis of metal ions ${ }^{31}$. Distribution ratios for $\mathrm{Mg}^{2+}$ and $\mathrm{Zn}^{2+}$ ions were found to increase with increases in $\mathrm{pH}$ values. However reverse effect of $\mathrm{pH}$ was observed on distribution ratios for $\mathrm{Sb}^{3+}$ and $\mathrm{Bi}^{3+}$ ions.

At $\mathrm{pH} 4$, the order of distribution ratio in HBTE-II resin was decreasing as $\mathrm{Bi}^{3+}>\mathrm{Sb}^{3+}>$ $\mathrm{Zn}^{2+}>\mathrm{Mg}^{2+}$. At $\mathrm{pH} 5$ and 6, the order of distribution ratio was same as follows $\mathrm{Zn}^{2+}>\mathrm{Mg}^{2+}$ $>\mathrm{Sb}^{3+}>\mathrm{Bi}^{3+}$. At $\mathrm{pH} 7$, the order of distribution ratio was $\mathrm{Zn}^{2+}>\mathrm{Mg}^{2+}>\mathrm{Bi}^{3+}>\mathrm{Sb}^{3+}$.

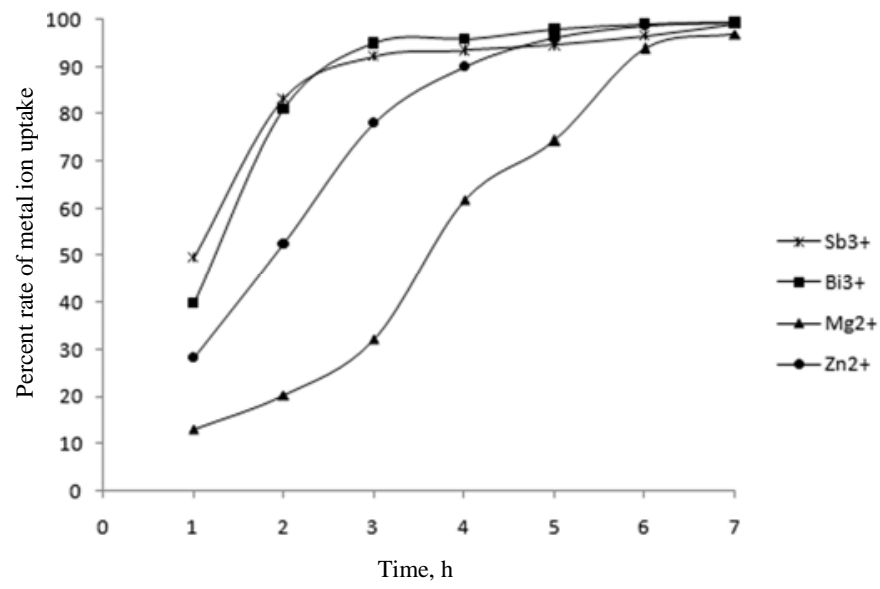

Figure 5. Metal ion uptake of HBTE-II terpolymer resin

Table 6. Distribution ratio (D) of different metal ions as a function of the $\mathrm{pH}$

\begin{tabular}{ccccc}
\hline \multirow{2}{*}{$\mathrm{pH}$} & \multicolumn{4}{c}{ Distribution ratio of the metal ion } \\
\cline { 2 - 5 } & $\mathrm{Sb}^{3+}$ & $\mathrm{Bi}^{3+}$ & $\mathrm{Mg}^{2+}$ & $\mathrm{Zn}^{2+}$ \\
\hline 4 & 129 & 450.7 & 96 & 117 \\
5 & 155 & 114.8 & 157 & 209 \\
6 & 95 & 91.7 & 215 & 464 \\
7 & 39 & 44.5 & 302 & 559 \\
\hline
\end{tabular}

Metal nitrate solution $=0.1 \mathrm{Mol} / \mathrm{L}, 5 \mathrm{~mL}$; Electrolyte $=\mathrm{NaNO}_{3}, 1.5 \mathrm{M}, 25 \mathrm{~mL}$; Equilibrium state $=$ $24 \mathrm{~h}$; Wt. of resin=25 mg; Temperature $=$ Room Temperature; Error $= \pm 1.5 \%$, Metal ions were estimated spectrophotometrically

\section{Conclusion}

The data of elemental analysis, FT-IR spectra, ${ }^{1} \mathrm{H}$ NMR spectra and UV-Visible spectra supports the structure of HBTE-II terpolymeric resin. Among the electrolytes such as $\mathrm{NaNO}_{3}$, $\mathrm{NaCl}, \mathrm{NaClO}_{4}$ and $\mathrm{Na}_{2} \mathrm{SO}_{4}$, the $\mathrm{NaNO}_{3}$ are found to be more suitable electrolyte supporting to the ion exchange of metal ion under study by HBTE-II resin. Trivalent metal ion shows comparatively higher rates of metal uptake than divalent. This may be due to electrostatic assistance to ion exchange process. HBTE-II terpolymer resin is a selective chelating ion exchange resin for metals as $\mathrm{Bi}^{3+}$ ions at $\mathrm{pH} 4$ and $\mathrm{Zn}^{2+}$ ions at $\mathrm{pH} 5$ to 7 in the mixture of $\mathrm{Sb}^{3+}$, $\mathrm{Bi}^{3+}, \mathrm{Mg}^{2+}$ and $\mathrm{Zn}^{2+}$ metal ions. The HBTE-II resin may be used to separate $\mathrm{Zn}^{2+}$ and $\mathrm{Bi}^{3+}$ metal ions. Similarly it may be used to preconcentrate $\mathrm{Sb}^{3+}$ from the solution containing $\mathrm{Sb}^{3+}$ and $\mathrm{Bi}^{3+}$.

\section{Acknowledgement}

The Authors are thankful to the Director Dr. M. T. Bharambe, Institute of Science, Nagpur, Dr. R. H. Limsey, Head of the Department of Chemistry, Institute of Science, Nagpur for 
providing laboratory facilities, CIMFR unit, Nagpur for elemental analysis of the sample, Pharmacy Department, R.T.M. Nagpur University, Nagpur for FT-IR spectrum of the sample, Director STIC, Cochin University, Kerala for ${ }^{1} \mathrm{H}$ NMR spectrum of the sample, Nanotechnology Department, Shivaji Science College, Nagpur for UV-Visible spectrum of sample.

\section{References}

1. Shah B A, Shah A V and Shah P M, Malay Poly J., 2009, 4(2), 1-12.

2. $\quad$ Ameta R, Patel V and Joshi J, Iran Poly J., 2007, 16(9), 615-625.

3. Rahangdale S S, Zade A B and Gurnule W B, J Chem., 2009, 6(3), 835-843; DOI:10.1155/2009/502701.

4. $\quad$ Rahangdale S S, Zade A B and Gurnule W B, J Appl Poly Sci., 2008, 108(2), 747-756; DOI:10.1002/app.27722.

5. Azarudeen R S, M Ahamed A R, Jeyakumar D and Burkanudeen A R, Iran Poly J., 2009, 18(10), 821-832.

6. $\quad$ Pancholi H B and Patel M M, High Perf Poly., 1991, 3(4), 257-262.

7. $\quad$ Gupta A N, Hiwase V V and Kalambe A B, J Chem Pharma Res., 2012, 4(5), 2475-2482.

8. Gupta A N, Hiwase V V and Kalambe A B, Der Pharm Chem., 2012, 4(3), 1153-1159.

9. Hiwase V V, Kalambe A B, Khedkar K M and Deosarkar S D, J Chem., 2010, 7(1), 287-294; DOI:10.1155/2010/830484.

10. Rath D K, Nayak P L and Lenka S, J Appl Polym Sci., 1994, 51(9), 1679-1682; DOI:10.1002/app.1994.070510919.

11. Gurnule W B, Rahangdale P K, Paliwal L J and Kharat R B, Synth React Inorg Metal Org Chem., 2003, 33(7), 1187-1205; DOI:10.1081/SIM-120023486.

12. Patel J R, Sutaria D H and Patel M N, React Polym., 1995, 25(1), 17-23; DOI:10.1016/0923-1137(95)00003-2.

13. Tarase M V, Gurnule W B. and Zade A B, J Chem., 2009, 6(3), 639-650; DOI:10.1155/2009/164129.

14. Gurnule W B, Rahangdale P K, Paliwal L J and Kharat R B, Prog Crystal Grow Charact Mater., 2002, 45(1-2), 155-160; DOI:10.1016/S0960-8974(02)00042-6.

15. Manavalan R, Patel M M, Die Angew Makromol Chem., 1983, 184, 717-723.

16. Patel D B, Gurnule W B and Zade A B, Der Pharm Chem., 2011, 3(3), 341-353.

17. Pal T K and Kharat R B, Die Angew Makromol Chem., 1989, 173(1), 55-68.

18. Patel K D and Patel M M, Synth React Inorganic Metal Org Chem., 1993, 2(2), 299-325; DOI:10.1080/15533179308016638.

19. Urade D, Hiwase V and Kalambe A, Chem Sci Trans., 2012, 1(3), 604-611; DOI:10.7598/cst2012.255.

20. Karunakaran M, Vijayakumar C T, Magesh C and Amudha T, Int J Eng Sci Tech., 2011, 3(1), 162-176.

21. Field L D, Sternell S and Kalman J R, Org Struct From spectra, John Willey and Sons, New York, 1969, 2, 299.

22. Silverstein R. M and Webster F X, Spectrometric Identification of Organic Compounds, $6^{\text {th }}$ Ed., John Wiley, New York, 217-248, 1998.

23. Singru R N, Zade A B and Gurunule W B, J Appl Polym Sci., 2008, 109, 859-868; DOI: 10.1002/app.28197.

24. Hirani B L, Paliwal S N, Choudhary J and Choudhary P R, J Chem., 2007, 4(2), 265-271; DOI:10.1155/2007/234768.

25. Bastia T K, Lenka S and Nayak P L, J Appl Polym Sci., 1992, 46, 739-744; DOI:10.1002/app.1992.070460421. 
26. Gurnule W B, Rahangdale P K, Paliwal L J and Kharat R B, J Appl Poly Sci., 2003, 89(3), 787-790; DOI:10.1002/app.12278.

27. Gurnule W B, Rahangdale P K, Kharat R B and Paliwal L, J, Prog Crystal Grow Charact Mater., 2002, 45(1-2), 133-138; DOI:10.1016/S0960-8974(02)00038-4.

28. Gurnule W B, Rahangdale P K, Paliwal L J and Kharat R B, React Funct Poly., 2003, 55(3), 255-265; DOI:10.1016/S1381-5148(03)00016-6.

29. Gurnule W B, Juneja H D and Paliwal L J, React Funct Poly., 2002, 50(2), 95-100; DOI:10.1016/S1381-5148(01)00072-4.

30. Gurnule W B, Juneja H D and Paliwal L J, Ultra Sci., 2001, 13(3), 333-339.

31. Tarase M V, Zade A B and Gurnule W B, J Appl Polym Sci., 2008, 108(2), 738-746; DOI:10.1002/app.27721. 